\title{
Common Fixed Point Theorems Satisfying Implicit Relations on 2-cone Banach Space with an Application
}

\author{
D. Dhamodharan*, Nihal Taş and R. Krishnakumar
}

\begin{abstract}
In this paper, we discuss the existence and uniqueness of common fixed-point theorems satisfying implicit relations on 2-cone Banach spaces. Modifying obtained new contractive conditions, we also give an application to the fixed-circle problem.
\end{abstract}

Keywords: common fixed point; 2-cone Banach space; 2-cone normed space; fixed circle.

AMS Subject Classification (2010): Primary: $47 \mathrm{H} 10$; Secondary: $54 \mathrm{H} 25$.

${ }^{*}$ Corresponding author

\section{Introduction and preliminaries}

In 2007, Huang and Zhang [3] introduced the concept of a cone metric space and proved fixed point theorems for contraction mappings such as:

Any mapping $T$ of a complete cone metric space $X$ into itself that satisfies, for some $0 \leq k<1$, the inequality

$$
d(T x, T y) \leq k d(x, y) \text { for all } x, y \in X
$$

has a unique fixed point.

In [4], Karapınar established some fixed-point theorems in cone Banach space in 2009. Ahmet Şahiner and Tuba Yiğit initiated the concept of a 2-cone Banach space and proved some fixed-point theorems [16]. Krishnakumar and Dhamodharan proved some common fixed-point theorems on contractive modulus in 2-cone Banach space [5].

In this paper, following the idea which was given in [14], we establish some common fixed-point theorems for a self-mapping satisfying implicit relations which are contractive conditions in 2-cone Banach spaces. Now we recall some known definitions and basic facts.

Definition 1.1. [3] Let $E$ be the real Banach space. A subset $P$ of $E$ is called a cone if and only if

1. $P$ is closed, nonempty and $P \neq 0$

2. $a x+b y \in P$ for all $x, y \in P$ and nonnegative real numbers $a, b$

3. $P \cap(-P)=\{0\}$.

Given a cone $P \subset E$, we define a partial ordering $\leq$ with respect to $P$ by $x \leq y$ if and only if $y-x \in P$. We will write $x<y$ to indicate that $x \leq y$ but $x \neq y$, while $x, y$ will stand for $y-x \in \operatorname{int} P$, where int $P$ denotes the interior of $P$. The cone $P$ is called normal if there is a number $K>0$ such that $0 \leq x \leq y$ implies $\|x\| \leq K\|y\|$ for all $x, y \in E$. The least positive number satisfying the above is called the normal constant.

From now on we suppose that $E$ is a Banach space, $P$ is a cone in $E$ with int $P=\emptyset$ and $\leq$ is partial ordering with respect to $P$.

Received : 24-01-2019, Accepted : 25-03-2019 
Example 1.1. Let $K>1$ be given. Consider the real vector space with

$$
E=\left\{a x+b: a, b \in R ; x \in\left[1-\frac{1}{k}, 1\right]\right\}
$$

with supremum norm and the cone

$$
P=\{a x+b: a \geq 0, b \leq 0\}
$$

in $E$. The cone $P$ is regular and so normal.

Definition 1.2. [3] Let $X$ be a nonempty set. If the mapping $d: X \times X \rightarrow E$ satisfies

1. $d(x, y)>0$ and $d(x, y)=0$ if and only if $x=y$ for all $x, y \in X$,

2. $d(x, y)=d(y, x)$ for all $x, y \in X$,

3. $d(x, y) \leq d(x, z)+d(z, y)$ for all $x, y, z \in X$,

then $(X, d)$ is called a cone metric space $(C M S)$.

Example 1.2. [3] Let $E=\mathbb{R}^{2}$

$$
P=\{(x, y): x, y \geq 0\}
$$

$X=\mathbb{R}$ and $d: X \times X \rightarrow E$ such that

$$
d(x, y)=(|x-y|, \alpha|x-y|),
$$

where $\alpha \geq 0$ is a constant. Then $(X, d)$ is a cone metric space.

Definition 1.3. [4] Let $X$ be a vector space over $\mathbb{R}$. If the mapping $\|\cdot\|_{c}: X \rightarrow E$ satisfies

1. $\|x\|_{c} \geq 0$ for all $x \in X$,

2. $\|x\|_{c}=0$ if and only if $x=0$,

3. $\|x+y\|_{c} \leq\|x\|_{c}+\|y\|_{c}$ for all $x, y \in X$,

4. $\|k x\|_{c}=|k|\|x\|_{c}$ for all $k \in \mathbb{R}$ and for all $x \in X$,

then $\|\cdot\|_{c}$ is called a cone norm on $X$, and the pair $\left(X,\|\cdot\|_{c}\right)$ is called a cone normed space $(C N S)$.

Remark 1.1. [1] Each cone normed space is cone metric space with metric defined by

$$
d(x, y)=\|x-y\|_{c} .
$$

Example 1.3. [15] Let $X=\mathbb{R}^{2}, P=\{(x, y): x \geq 0, y \geq 0\} \subset \mathbb{R}^{2}$ and $\|(x, y)\|_{c}=(a|x|, b|y|), a>0, b>0$. Then $\left(X,\|\cdot\|_{c}\right)$ is a cone normed space over $\mathbb{R}^{2}$.

Example 1.4. [2] Let $E=l_{1}, P=\left\{\left\{x_{n}\right\} \in E: x_{n} \geq 0\right.$, for all $\left.n\right\}$ and $(X,\|\cdot\|)$ be a normed space and $\|\cdot\|_{c}: X \rightarrow E$ defined by $\|x\|_{c}=\left\{\frac{\|x\|}{2^{n}}\right\}$. Then $P$ is a normal cone with constant normal $M=1$ and $\left(X,\|\cdot\|_{c}\right)$ is a cone normed space.

Definition 1.4. [1] Let $\left(X,\|.\|_{c}\right)$ be a $C N S, x \in X$ and $\left\{x_{n}\right\}_{n \geq 0}$ be a sequence in $X$. Then $\left\{x_{n}\right\}_{n \geq 0}$ converges to $x$ whenever for every $c \in E$ with $0 \ll E$, there is a natural number $N \in \mathbb{N}$ such that $\left\|x_{n}-x\right\|_{c} \ll c$ for all $n \geq N$. It is denoted by $\lim _{n \rightarrow \infty} x_{n}=x$ or $x_{n} \rightarrow x$.

Definition 1.5. [1] Let $\left(X,\|.\|_{c}\right)$ be a $C N S, x \in X$ and $\left\{x_{n}\right\}_{n \geq 0}$ be a sequence in $X .\left\{x_{n}\right\}_{n \geq 0}$ is a Cauchy sequence whenever for every $c \in E$ with $0 \ll c$, there is a natural number $N \in \mathbb{N}$, such that $\left\|x_{n}-x_{m}\right\|_{c} \ll c$ for all $n, m \geq N$.

Definition 1.6. [1] Let $\left(X,\|\cdot\|_{c}\right)$ be a $C N S, x \in X$ and $\left\{x_{n}\right\}_{n \geq 0}$ be a sequence in $X$. $\left(X,\|\cdot\|_{c}\right)$ is a complete cone normed space if every Cauchy sequence is convergent. Complete cone normed spaces will be called cone Banach spaces.

Lemma 1.1. [4] Let $\left(X,\|.\|_{c}\right)$ be a $C N S, P$ be a normal cone with normal constant $K$, and $\left\{x_{n}\right\}$ be a sequence in $X$. Then 
i. the sequence $\left\{x_{n}\right\}$ converges to $x$ if and only if $\left\|x_{n}-x\right\|_{c} \rightarrow 0$ as $n \rightarrow \infty$,

ii. the sequence $\left\{x_{n}\right\}$ is Cauchy if and only if $\left\|x_{n}-x_{m}\right\|_{c} \rightarrow 0$ as $n, m \rightarrow \infty$,

iii. the sequence $\left\{x_{n}\right\}$ converges to $x$ and the sequence $\left\{y_{n}\right\}$ converges to $y$, then $\left\|x_{n}-y_{n}\right\|_{c} \rightarrow\|x-y\|_{c}$.

Definition 1.7. [16] Let $X$ be a linear space over $\mathbb{R}$ with dimension greater then or equal to 2, $E$ be Banach space with the norm $\|\cdot\|$ and $P \subset E$ be a cone. If the function

$$
\|., .\|: X \times X \rightarrow(E, P,\|\cdot\|)
$$

satisfies the following axioms then $\left(X,\|., .\|_{c}\right)$ is called a 2-cone normed space:

1. $\|x, y\|_{c} \geq 0$ for all $x, y \in X,\|x, y\|_{c}=0$ if and only if $x$ and $y$ are linearly dependent,

2. $\|x, y\|_{c}=\|y, x\|_{c}$ for all $x, y \in X$,

3. $\|\alpha x, y\|_{c}=|\alpha|\|x, y\|_{c}$ for all $x, y \in X$ and $\alpha \in \mathbb{R}$,

4. $\|x, y+z\|_{c} \leq\|x, y\|_{c}+\|y, z\|_{c}$ for all $x, y, z \in X$.

If we fix $\left\{u_{1}, u_{2}, \ldots, u_{d}\right\}$ to be a basis for $X$, we can give the following lemma.

Lemma 1.2. [16] Let $\left(X,\|., .\|_{c}\right)$ be a 2-cone normed space. Then a sequence $\left\{x_{n}\right\}$ converges to $x \in X$ if and only if for each $c \in E$ with $c \gg 0$ ( 0 is zero element of $E$ ) there exists an $N=N(c) \in \mathbb{N}$ such that $n>N$ implies $\left\|x_{n}-x, u_{i}\right\|_{c} \ll c$ for every $i=1,2, \ldots, d$.

Lemma 1.3. [16] Let $\left(X,\|.,\|_{c}\right)$ be a 2-cone normed space. Then a sequence $\left\{x_{n}\right\}$ converges to $x$ in $X$ if and only if $\lim _{n \rightarrow \infty} \max \left\|x_{n}-x, u_{i}\right\|_{c}=0$.

Definition 1.8. [16] A 2-cone normed space $\left(X,\|., .\|_{c}\right)$ is a 2-cone Banach space if any Cauchy sequence in $X$ is convergent to an $x$ in $X$.

Theorem 1.1. [17] Any 2-cone normed space $X$ is a cone normed spaces and its topology agrees with the norm generated by $\|.\|_{c}^{\infty}$, where the function $\|.\|_{c}^{\infty}: X \rightarrow(E, P,\|\cdot\|)$ is defined by

$$
\|\cdot\|_{c}^{\infty}:=\max \left\{\left\|x, u_{i}\right\|_{c}: i=1,2, \ldots, d\right\} .
$$

\section{Main results}

In this section, we prove some common fixed-point theorems on 2-cone Banach spaces. To do this, we define some notions and give some necessary examples.

Definition 2.1. Let $X$ be a 2-cone Banach space (with $\operatorname{dim} X \geq 2$ ) and $T$ be a self-mapping of $X$. If $T$ satisfies the condition

$$
\|T x-T y, u\|_{c} \leq h_{1}\|x-y, u\|_{c}
$$

for all $x, y, u \in X$ and some $0<h_{1}<1$ then it is called 2-Banach contraction.

Definition 2.2. Let $X$ be a 2-cone Banach space (with $\operatorname{dim} X \geq 2$ ) and $T$ be a self mapping of $X$. A mapping $T$ is said to be 2-Zamfirescu type contraction if it satisfies at least one of the conditions for all $x, y, u \in X$ and some $h_{1} \in(0,1), h_{2}, h_{3} \in\left(0, \frac{1}{2}\right):$

1. $\|T x-T y, u\|_{c} \leq h_{1}\|x-y, u\|_{c}$

2. $\|T x-T y, u\|_{c} \leq h_{2}\left(\|x-T y, u\|_{c}+\|y-T x, u\|_{c}\right)$,

3. $\|T x-T y, u\|_{c} \leq h_{3}\left(\|x-T x, u\|_{c}+\|y-T y, u\|_{c}\right)$.

Definition 2.3. Let $X$ be a 2-cone Banach space and $T$ be a self mapping of $X$. T is said to be continuous at $x$ if for all sequence $\left\{x_{n}\right\}$ in $X$ with $\left\|x_{n}, u\right\|_{c} \rightarrow\|x, u\|_{c}$ implies that $\left\|T x_{n}, u\right\|_{c} \rightarrow\|T x, u\|_{c}$. 
Lemma 2.1. Let $X$ and $Y$ be two 2-cone Banach spaces and $T$ be a linear map from $X$ into $Y$. The following properties are equivalent:

$i$ (Continuity at a point) Given $0 \ll c$ there is $a \quad 0 \ll s$ such that $\left\|T x-T x_{0}, u\right\|_{c} \ll c$ whenever $\left\|x-x_{0}, u\right\|_{c} \ll s$ for some $x_{0} \in X$.

ii (Continuity at zero) For $0 \ll c$ there is $a 0 \ll s$ such that $\|T x, u\|_{c} \ll c$ whenever $\|x, u\|_{c} \ll s$.

iii (Continuity at every point of $x$ ) Given $0 \ll c$ there is $a 0 \ll s$ such that $\|T x-T y, u\|_{c} \ll c$ whenever $\|x-y, u\|_{c} \ll s$ for some $x \in X$.

Proof. Assume that (i) is true. For some $x_{0} \in X$ and for every $0 \ll c$ there is a $0 \ll s$ such that $\left\|T x-T x_{0}, u\right\|_{c} \ll c$ whenever $\left\|x-x_{0}, u\right\|_{c} \ll s$. Then for every $z \in X$ with $\|z, u\|_{c} \ll s$ we have $\left\|T\left(z+x_{0}\right)-T x_{0}, u\right\|_{c} \ll c$ because $\left\|\left(z+x_{0}\right)-x_{0}, u\right\|_{c} \ll t$, where $T$ is linear map then $\|T z, u\|_{c} \ll c$ whenever $\|z, u\|_{c} \ll s$ and we have shown that (i) implies (ii).

Assume that (ii) is true. For every $x \in X$ and $0 \ll c$, there exits a $0 \ll s$ such that $\|T z, u\|_{c} \ll c$ whenever $\|z, u\|_{c} \ll s$ then we have $\|T(y-x), u\|_{c} \ll s$. If we take $y-x$ in place of $z$ then we have (ii) implies (iii) since $T$ is linear map. Clearly (iii) implies (i). Thus (i), (ii) and (iii) are equivalent.

Definition 2.4. Let $\Phi$ be the class of continuous functions $\varphi: P^{4} \rightarrow P$ non-decreasing in the first argument and if $\varphi$ satisfies one of the following conditions for $x, y \in P$ :

a. $\left(a_{1}\right) x \leq \varphi\left(y, x, y, \frac{x+y}{2}\right)$ or $\left(a_{2}\right) x \leq \varphi(x, y, y, x)$.

b. $\left(b_{1}\right) x \leq \varphi\left(y, \frac{x+y}{2}, 0, x+y\right)$ or $\left(b_{2}\right) x \leq \varphi(x, y, x, x)$.

then there exists a real number $0<h<1$ such that $x \leq h y$.

Now we define the following conditions:

Condition (I): Let $X$ be a 2-cone Banach space (with $\operatorname{dim} X \geq 2$ ) and $S, T$ be two self-mappings of $X$ such that for all $x, y, u \in X$ satisfying the condition:

$$
\|S x-T y, u\|_{c} \leq \varphi\left(\|x-y, u\|_{c},\|x-S x, u\|_{c},\|y-T y, u\|_{c}, \frac{\|x-T y, u\|_{c}+\|y-S x, u\|_{c}}{2}\right) .
$$

Condition (II): Let $X$ be a 2-cone Banach space (with $\operatorname{dim} X \geq 2$ ) and $S, T$ be two self-mappings of $X$ such that for all $x, y, u \in X$ satisfying the condition:

$$
\|S x-T y, u\|_{c} \leq \varphi\left(\|x-y, u\|_{c}, \frac{\|x-S x, u\|_{c}+\|y-T y, u\|_{c}}{2}, 0,\|x-T y, u\|_{c}+\|y-S x, u\|_{c}\right) .
$$

Theorem 2.1. Let $X$ be a 2-cone Banach space (with $\operatorname{dim} X \geq 2$ ) and $S, T$ be two continuous self-mappings of $X$ satisfying the condition (I). Then $S$ and $T$ have a unique common fixed point in $X$.

Proof. For a given $x_{0} \in X$ and $n \geq 1$, take $x_{1}, x_{2} \in X$ such that $x_{1}=S x_{0}$ and $x_{2}=T x_{1}$. In general we define a sequence of elements of $X$ such that $x_{2 n+1}=S x_{2 n}$ and $x_{2 n}=T x_{2 n-1}$ for $n=0,1,2,3, \cdots$. Now for all $u \in X$, by condition $(I)$, we obtain

$$
\begin{aligned}
\left\|x_{2 n+1}-x_{2 n}, u\right\|_{c} & =\left\|S x_{2 n}-T x_{2 n-1}, u\right\|_{c} \\
& \leq \varphi\left(\begin{array}{c}
\left\|x_{2 n}-x_{2 n-1}, u\right\|_{c},\left\|x_{2 n}-S x_{2 n}, u\right\|_{c},\left\|x_{2 n-1}-T x_{2 n-1}, u\right\|_{c}, \\
\frac{\left\|x_{2 n}-T x_{2 n-1}, u\right\|_{c}+\left\|x_{2 n-1}-S x_{2 n}, u\right\|_{c}}{2}
\end{array}\right) \\
& =\left(\begin{array}{c}
\varphi x_{2 n}-x_{2 n-1}, u\left\|_{c},\right\| x_{2 n}-x_{2 n+1}, u\left\|_{c},\right\| x_{2 n-1}-x_{2 n}, u \|_{c}, \\
\frac{\left\|x_{2 n}-x_{2 n}, u\right\|_{c}+\left\|x_{2 n-1}-x_{2 n+1}, u\right\|_{c}}{2}
\end{array}\right) \\
& =\varphi\left(\begin{array}{c}
\left\|x_{2 n}-x_{2 n-1}, u\right\|_{c},\left\|x_{2 n}-x_{2 n+1}, u\right\|_{c},\left\|x_{2 n}-x_{2 n-1}, u\right\|_{c}, \\
\frac{\left\|x_{2 n-1}-x_{2 n+1}, u\right\|_{c}}{2}
\end{array}\right) \\
& \leq \varphi\left(\begin{array}{c}
\left\|x_{2 n}-x_{2 n-1}, u\right\|_{c},\left\|x_{2 n}-x_{2 n+1}, u\right\|_{c},\left\|x_{2 n}-x_{2 n-1}, u\right\|_{c} \\
\frac{\left\|x_{2 n-1}-x_{2 n}, u\right\|_{c}+\left\|x_{2 n}-x_{2 n+1}, u\right\|_{c}}{2}
\end{array}\right) .
\end{aligned}
$$


Hence from Definition $2.4\left(a_{1}\right)$, we have

$$
\left\|x_{2 n+1}-x_{2 n}, u\right\|_{c} \leq h\left\|x_{2 n}-x_{2 n-1}, u\right\|_{c} \text { where } 0<h<1 .
$$

Similarly, we have

$$
\left\|x_{2 n}-x_{2 n-1}, u\right\|_{c} \leq h\left\|x_{2 n-1}-x_{2 n-2}, u\right\|_{c} .
$$

Hence, by (2.1) and (2.2), we have

$$
\left\|x_{2 n+1}-x_{2 n}, u\right\|_{c} \leq h^{2}\left\|x_{2 n-1}-x_{2 n-2}, u\right\|_{c} .
$$

By continuing this process, we get

$$
\left\|x_{2 n+1}-x_{2 n}, u\right\|_{c} \leq h^{2 n}\left\|x_{1}-x_{0}, u\right\|_{c} .
$$

For every $n>m$, we have

$$
\begin{aligned}
\left\|x_{n}-x_{m}, u\right\|_{c} & \leq\left\|x_{n}-x_{n-1}, u\right\|_{c}+\left\|x_{n-1}-x_{n-2}, u\right\|_{c}+\cdots+\left\|x_{m+1}-x_{m}, u\right\|_{c} \\
& \leq\left(h^{n-1}+h^{n-2}+\cdots+h^{m}\right)\left\|x_{1}-x_{0}, u\right\|_{c} \\
& \leq\left(\frac{h^{m}}{1-h}\right)\left\|x_{1}-x_{0}, u\right\|_{c} .
\end{aligned}
$$

Since $0<h<1$, by Definition 2.4, $\left(\frac{h^{m}}{1-h}\right)<<0$ as $m \rightarrow \infty$. Hence $\left\|x_{n}-x_{m}, u\right\|_{c}<<0$ as $n, m \rightarrow \infty$. This shows that $\left\{x_{n}\right\}$ is a Cauchy sequence in $X$. Hence there exists a point $z$ in $X$ such that $x_{n} \rightarrow z$ as $n \rightarrow \infty$. It follows from the continuity of $S$ and $T$ that $S z=T z=z$. Thus $z$ is a common fixed point of $S$ and $T$.

Uniqueness Let $w$ be another common fixed point of $S$ and $T$, that is $S w=T w=w$. Then, we have

$$
\begin{aligned}
\|z-w, u\|_{c} & =\|S z-T w, u\|_{c} \\
& \leq \varphi\left(\begin{array}{c}
\|z-w, u\|_{c},\|z-S z, u\|_{c},\|w-T w, u\|_{c}, \\
\frac{\|z-T w, u\|_{c}+\|w-S z, u\|_{c}}{2}
\end{array}\right) \\
& \leq \varphi\left(\|z-w, u\|_{c}, 0,0,\|z-w, u\|_{c}\right) .
\end{aligned}
$$

By Definition $2.4\left(a_{2}\right)$ and the inequality (2.3), we get

$$
\|z-w, u\|_{c} \leq 0
$$

Hence $z=w$ and for all $u \in X$. Thus $z$ is a unique common fixed point of $S$ and $T$.

Corollary 2.1. Let $X$ be a 2-cone Banach space (with $\operatorname{dim} X \geq 2$ ) and $T$ be a self-mapping of $X$ satisfying the condition

$$
\|T x-T y, u\|_{c} \leq \varphi\left(\|x-y, u\|_{c},\|x-T x, u\|_{c},\|y-T y, u\|_{c}, \frac{\|x-T y, u\|_{c}+\|y-T x, u\|_{c}}{2}\right),
$$

for all $x, y, u \in X$. Then $T$ has a unique fixed point in $X$.

Proof. The proof of corollary has immediately follows from above Theorem 2.1 by taking $S=T$. This completes the proof.

From the above theorem, we obtain the following results as special cases.

Theorem 2.2. Let $X$ be a 2-cone Banach space (with $\operatorname{dim} X \geq 2$ ) and $T, S$ be two self-mappings of $X$ satisfying the condition

$$
\|S x-T y, u\|_{c} \leq h_{1}\|x-y, u\|_{c},
$$

for all $x, y, u \in X, 0<h_{1}<1$. Then $T$ and $S$ have a unique common fixed point in $X$.

Theorem 2.3. Let $X$ be a 2-cone Banach space (with $\operatorname{dim} X \geq 2$ ) and $T, S$ be two self-mappings of $X$ satisfying the condition

$$
\|S x-T y, u\|_{c} \leq h_{2}\left(\|x-T y, u\|_{c}+\|y-S x, u\|_{c}\right),
$$

for all $x, y, u \in X, 0<h_{2}<\frac{1}{2}$. Then $T$ and $S$ have a unique common fixed point in $X$. 
We prove the following theorem using the condition $(I I)$.

Theorem 2.4. Let $X$ be a 2-cone Banach space (with $\operatorname{dim} X \geq 2$ ) and $S, T$ be two continuous self-mappings of $X$ satisfying the condition (II). Then $S$ and $T$ have a unique common fixed point in $X$.

Proof. For a given $x_{0} \in X$ and $n \geq 1$, take $x_{1}, x_{2} \in X$ such that $x_{1}=S x_{0}$ and $x_{2}=T x_{1}$. In general we define a sequence of elements of $X$ such that $x_{2 n+1}=S x_{2 n}$ and $x_{2 n}=T x_{2 n-1}$ for $n=0,1,2,3, \cdots$. Now for all $u \in X$, by condition $(I I)$, we obtain

$$
\begin{aligned}
\left\|x_{2 n+1}-x_{2 n}, u\right\|_{c} & =\left\|S x_{2 n}-T x_{2 n-1}, u\right\|_{c} \\
& \leq \varphi\left(\begin{array}{c}
\left\|x_{2 n}-x_{2 n-1}, u\right\|_{c}, \frac{\left\|x_{2 n-1}-T x_{2 n-1}, u\right\|_{c}+\left\|x_{2 n}-S x_{2 n}, u\right\|_{c}}{2} \\
\left\|x_{2 n}-T x_{2 n-1}, u\right\|_{c},\left\|x_{2 n-1}-S x_{2 n}, u\right\|_{c}
\end{array}\right) \\
& =\varphi\left(\begin{array}{c}
\left\|x_{2 n}-x_{2 n-1}, u\right\|_{c}, \frac{\left\|x_{2 n-1}-x_{2 n}, u\right\|_{c}+\left\|x_{2 n}-x_{2 n+1}, u\right\|_{c}}{2} \\
\left\|x_{2 n}-x_{2 n}, u\right\|_{c},\left\|x_{2 n}-x_{2 n+1}, u\right\|_{c}
\end{array}\right) \\
& =\varphi\left(\begin{array}{c}
\left\|x_{2 n}-x_{2 n-1}, u\right\|_{c}, \frac{\left\|x_{2 n-1}-x_{2 n}, u\right\|_{c}+\left\|x_{2 n}-x_{2 n+1}, u\right\|_{c}}{2} \\
0,\left\|x_{2 n}-x_{2 n+1}, u\right\|_{c}
\end{array}\right) \\
& \leq \varphi\left(\begin{array}{c}
\left\|x_{2 n}-x_{2 n-1}, u\right\|_{c}, \frac{\left\|x_{2 n-1}-x_{2 n}, u\right\|_{c}+\left\|x_{2 n}-x_{2 n+1}, u\right\|_{c}}{2} \\
0,\left\|x_{2 n-1}-x_{2 n}, u\right\|_{c}+\left\|x_{2 n}-x_{2 n+1}, u\right\|_{c}
\end{array}\right) .
\end{aligned}
$$

Hence from Definition $2.4\left(b_{1}\right)$, we have

$$
\left\|x_{2 n+1}-x_{2 n}, u\right\|_{c} \leq h\left\|x_{2 n}-x_{2 n-1}, u\right\|_{c} \text { where } 0<h<1 .
$$

Similarly, we have

$$
\left\|x_{2 n}-x_{2 n-1}, u\right\|_{c} \leq h\left\|x_{2 n-1}-x_{2 n-2}, u\right\|_{c} .
$$

Hence from (2.4) and (2.5), we have

$$
\left\|x_{2 n+1}-x_{2 n}, u\right\|_{c} \leq h^{2}\left\|x_{2 n-1}-x_{2 n-2}, u\right\|_{c}
$$

on continuing this process, we get

$$
\left\|x_{2 n+1}-x_{2 n}, u\right\|_{c} \leq h^{2 n}\left\|x_{1}-x_{0}, u\right\|_{c} .
$$

For every $n>m$, we have

$$
\begin{aligned}
\left\|x_{n}-x_{m}, u\right\|_{c} & \leq\left\|x_{n}-x_{n-1}, u\right\|_{c}+\left\|x_{n-1}-x_{n-2}, u\right\|_{c}+\cdots+\left\|x_{m+1}-x_{m}, u\right\|_{c} \\
& \leq\left(h^{n-1}+h^{n-2}+\cdots+h^{m}\right)\left\|x_{1}-x_{0}, u\right\|_{c} \\
& \leq\left(\frac{h^{m}}{1-h}\right)\left\|x_{1}-x_{0}, u\right\|_{c}
\end{aligned}
$$

Since $0<h<1$, by Definition 2.4, $\left(\frac{h^{m}}{1-h}\right)<<0$ as $m \rightarrow \infty$. Hence $\left\|x_{n}-x_{m}, u\right\|_{c}<<0$ as $n, m \rightarrow \infty$. This shows that $\left\{x_{n}\right\}$ is a Cauchy sequence in $X$. Hence there exists a point $z$ in $X$ such that $x_{n} \rightarrow z$ as $n \rightarrow \infty$. It follows from the continuity of $S$ and $T$ that $S z=T z=z$. Thus $z$ is a common fixed point of $S$ and $T$.

Uniqueness Let $w$ be another common fixed point of $S$ and $T$, that is $S w=T w=w$. Then, we have

$$
\begin{aligned}
\|z-w, u\|_{c} & =\|S z-T w, u\|_{c} \\
& \leq \varphi\left(\begin{array}{c}
\|z-w, u\|_{c}, \frac{\|w-T w, u\|_{c}+\|z-S z, u\|_{c}}{2}, \\
\|z-T w, u\|_{c},\|w-S z, u\|_{c}
\end{array}\right) \\
& \leq \varphi\left(\|z-w, u\|_{c}, 0,\|z-w, u\|_{c},\|z-w, u\|_{c}\right) .
\end{aligned}
$$

By Definition $2.4\left(b_{2}\right)$ and the inequality (2.6), we get

$$
\|z-w, u\|_{c} \leq 0
$$

Hence $z=w$ and for all $u \in X$. Thus $z$ is a unique common fixed point of $S$ and $T$. 
Corollary 2.2. Let $X$ be a 2-cone Banach space (with $\operatorname{dim} X \geq 2$ ) and $T$ be a self-mapping of $X$ satisfying the condition

$$
\|T x-T y, u\|_{c} \leq \varphi\left(\|x-y, u\|_{c}, \frac{\|x-T x, u\|_{c}+\|y-T y, u\|_{c}}{2},\|x-T y, u\|_{c},\|y-T x, u\|_{c}\right),
$$

for all $x, y, u \in X$. Then $T$ has a unique fixed point in $X$.

Proof. The proof of corollary has immediately follows from above Theorem 2.4 by taking $S=T$. This completes the proof.

From the above theorem we obtain the following result as a special case.

Theorem 2.5. Let $X$ be a 2-cone Banach space (with $\operatorname{dim} X \geq 2$ ) and $T, S$ be two self-mappings of $X$ satisfying the condition

$$
\|S x-T y, u\|_{c} \leq h_{3}\left(\|x-S x, u\|_{c}+\|y-T y, u\|_{c}\right),
$$

for all $x, y, u \in X, 0<h_{3}<\frac{1}{2}$. Then $T$ and $S$ have a unique common fixed point in $X$.

From Theorem 2.1 and Theorem 2.4, we obtain the following results as special cases.

Theorem 2.6. Let $X$ be a 2-cone Banach space (with $\operatorname{dim} X \geq 2$ ) and $T, S$ be two self-mappings of $X$. A mapping $T$ and $S$ are said to be 2-Zamfirescu type contraction satisfying the at least one of the following conditions is true:

1. $\|S x-T y, u\|_{c} \leq h_{1}\|x-y, u\|_{c}$

2. $\|S x-T y, u\|_{c} \leq h_{2}\left(\|x-T y, u\|_{c}+\|y-S x, u\|_{c}\right)$

3. $\|S x-T y, u\|_{c} \leq h_{3}\left(\|x-S x, u\|_{c}+\|y-T y, u\|_{c}\right)$

for all $x, y, u \in X, h_{1} \in(0,1)$ and $h_{2}, h_{3} \in\left(0, \frac{1}{2}\right)$. Then $T$ and $S$ have a unique common fixed point in $X$.

\section{An application to the fixed-circle problem}

In this section, we give an application to the fixed-circle problem which is a new geometric approach to fixedpoint theory raised by Özgür and Taş [8]. More recently, some different solutions of the problem have been investigated with various techniques on metric spaces or some generalized metric spaces (see [6], [7], [9], [10], [11], [12], [13], [18], [19], [20] and [21] for more details). In this context, we obtain new fixed-circle theorems on 2-cone normed spaces. At first, we recall the notion of an open ball and define a circle on a 2-cone normed space.

Definition 3.1. [17] Let $\|\cdot\|_{c}^{\infty}: X \rightarrow(E, P,\|\|$.$) and r \in E$ with $r \gg \theta$. Then the set

$$
B_{\left\{u_{1}, u_{2}, \ldots, u_{d}\right\}}\left(x_{0}, r\right)=\left\{x:\left\|x-x_{0}\right\|_{c}^{\infty} \ll r\right\}
$$

is called an open ball centered at $x_{0}$ with radius $r$.

Definition 3.2. (1) Let $\|.\|_{c}^{\infty}: X \rightarrow(E, P,\|\|$.$) and r \in E$ with $r \gg \theta$ or $r=\theta$. Then the set

$$
C_{x_{0}, r}^{2}=C_{\left\{u_{1}, u_{2}, \ldots, u_{d}\right\}}\left(x_{0}, r\right)=\left\{x:\left\|x-x_{0}\right\|_{c}^{\infty}=r\right\}
$$

is called a circle centered at $x_{0}$ with radius $r$.

(2) Let $\|.\|_{c}^{\infty}: X \rightarrow(E, P,\|\cdot\|)$ and $r \in E$ with $r \gg \theta$ or $r=\theta$. Then the set

$$
B_{\left\{u_{1}, u_{2}, \ldots, u_{d}\right\}}\left[x_{0}, r\right]=B_{\left\{u_{1}, u_{2}, \ldots, u_{d}\right\}}\left(x_{0}, r\right) \cup C_{x_{0}, r}^{2}
$$

is called a closed ball centered at $x_{0}$ with radius $r$.

(3) The circle $C_{x_{0}, r}^{2}$ (or the closed ball $B_{\left\{u_{1}, u_{2}, \ldots, u_{d}\right\}}\left[x_{0}, r\right]$ ) is called as the fixed circle (or fixed disc) of a selfmapping $T$ if $T x=x$ for all $x \in C_{x_{0}, r}^{2}$ (or $\left.x \in B_{\left\{u_{1}, u_{2}, \ldots, u_{d}\right\}}\left[x_{0}, r\right]\right)$, respectively.

We give the following fixed-circle (or fixed-disc) results: 
Theorem 3.1. Let $X$ be a 2-cone normed space (with $\operatorname{dim} X \geq 2$ ), $T: X \rightarrow X$ be a self-mapping, $x_{0} \in X$ and

$$
r=\inf _{x \in X}\left\{\|T x-x, u\|_{c}: T x \neq x\right\} .
$$

If $T$ satisfies the following conditions, then $C_{x_{0}, r}^{2}$ is a fixed circle of $T$ :

(1) If $T x \neq x$ then

$$
\|T x-x, u\|_{c} \leq \varphi\left(\begin{array}{c}
\left\|x-x_{0}, u\right\|_{c},\|T x-x, u\|_{c},\left\|x-T x_{0}, u\right\|_{c} \\
\frac{\left\|x-T x_{0}, u\right\|_{c}+\|T x-x, u\|_{c}}{2}
\end{array}\right)
$$

where $\varphi \in \Phi$.

(2) $T x_{0}=x_{0}$.

Proof. Case 1: Let $r=\theta$. Then we have

$$
\begin{aligned}
\left\|x-x_{0}\right\|_{c}^{\infty} & =\theta \Longrightarrow \max \left\{\left\|x-x_{0}, u_{i}\right\|_{c}: i=1,2, \ldots d\right\}=0 \\
& \Longrightarrow\left\|x-x_{0}, u_{i}\right\|_{c}=0 \text { for all } i=1,2, \ldots d \\
& \Longrightarrow x=x_{0} \\
& \Longrightarrow C_{x_{0}, r}^{2}=\left\{x_{0}\right\} .
\end{aligned}
$$

Using the condition (2), we know $T x_{0}=x_{0}$ and so $C_{x_{0}, r}^{2}$ is a fixed circle of $T$.

Case 2: Let $r \gg \theta$ and $x \in C_{x_{0}, r}^{2}$ with $T x \neq x$. By the definition of $r$, we have $r \leq\|T x-x, u\|_{c}$. Using the conditions (1), (2) and the property of $\varphi$, we obtain

$$
\begin{aligned}
\|T x-x, u\|_{c} & \leq \varphi\left(\begin{array}{c}
\left\|x-x_{0}, u\right\|_{c},\|T x-x, u\|_{c},\left\|x-T x_{0}, u\right\|_{c}, \\
\frac{\left\|x-T x_{0}, u\right\|_{c}+\|T x-x, u\|_{c}}{2}
\end{array}\right) \\
& \leq \varphi\left(r,\|T x-x, u\|_{c}, r, \frac{r+\|T x-x, u\|_{c}}{2}\right) .
\end{aligned}
$$

From Definition $2.4\left(a_{1}\right)$, we have

$$
\|T x-x, u\|_{c} \leq h r, h \in(0,1),
$$

which is a contradiction with the definition of $r$. Therefore, it should be $T x=x$. Consequently, $C_{x_{0}, r}^{2}$ is a fixed circle of $T$.

Corollary 3.1. Let $X$ be a 2-cone normed space (with $\operatorname{dim} X \geq 2$ ), $T: X \rightarrow X$ be a self-mapping, $x_{0} \in X$ and $r$ be defined as in (3.1). If $T$ satisfies the following conditions, then $T$ fixes the closed ball $B_{\left\{u_{1}, u_{2}, \ldots, u_{d}\right\}}\left[x_{0}, \rho\right]$ with $\rho \leq r$ (or $B_{\left\{u_{1}, u_{2}, \ldots, u_{d}\right\}}\left[x_{0}, r\right]$ is the fixed disc of $\left.T\right)$ :

(1) If $T x \neq x$ then

$$
\|T x-x, u\|_{c} \leq \varphi\left(\begin{array}{c}
\left\|x-x_{0}, u\right\|_{C},\|T x-x, u\|_{c},\left\|x-T x_{0}, u\right\|_{c} \\
\frac{\left\|x-T x_{0}, u\right\|_{c}+\|T x-x, u\|_{c}}{2}
\end{array}\right)
$$

where $\varphi \in \Phi$.

(2) $T x_{0}=x_{0}$.

Proof. The proof can be easily seen by the similar arguments used in the proof of Theorem 3.1.

Theorem 3.2. Let $X$ be a 2-cone normed space (with $\operatorname{dim} X \geq 2$ ), $T: X \rightarrow X$ be a self-mapping, $x_{0} \in X$ and $r$ be defined as in (3.1). If $T$ satisfies the following conditions, then $C_{x_{0}, r}^{2}$ is a fixed circle of $T$ :

(1) If $T x \neq x$ then

$$
\|T x-x, u\|_{c} \leq \varphi\left(\begin{array}{c}
\left\|x-x_{0}, u\right\|_{c}, \frac{\left\|x-T x_{0}, u\right\|_{c}+\|T x-x, u\|_{c}}{2}, 0 \\
\|T x-x, u\|_{c}+\left\|x-T x_{0}, u\right\|_{c}
\end{array}\right)
$$

where $\varphi \in \Phi$.

(2) $T x_{0}=x_{0}$. 
Proof. Case 1: Let $r=\theta$. Then we have $C_{x_{0}, r}^{2}=\left\{x_{0}\right\}$. Using the condition (2), we know $T x_{0}=x_{0}$ and so $C_{x_{0}, r}^{2}$ is a fixed circle of $T$.

Case 2: Let $r \gg \theta$ and $x \in C_{x_{0}, r}^{2}$ with $T x \neq x$. By the definition of $r$, we have $r \leq\|T x-x, u\|_{c}$. Using the conditions (1), (2) and the property of $\varphi$, we obtain

$$
\begin{aligned}
\|T x-x, u\|_{c} & \leq \varphi\left(\begin{array}{c}
\left\|x-x_{0}, u\right\|_{c}, \frac{\left\|x-T x_{0}, u\right\|_{c}+\|T x-x, u\|_{c}}{2}, 0, \\
\|T x-x, u\|_{c}+\left\|x-T x_{0}, u\right\|_{c}
\end{array}\right) \\
& \leq \varphi\left(r, \frac{r+\|T x-x, u\|_{c}}{2}, 0,\|T x-x, u\|_{c}+r\right) .
\end{aligned}
$$

From Definition $2.4\left(b_{1}\right)$, we have

$$
\|T x-x, u\|_{c} \leq h r, h \in(0,1),
$$

which is a contradiction with the definition of $r$. Therefore, it should be $T x=x$. Consequently, $C_{x_{0}, r}^{2}$ is a fixed circle of $T$.

Corollary 3.2. Let $X$ be a 2-cone normed space (with $\operatorname{dim} X \geq 2$ ), $T: X \rightarrow X$ be a self-mapping, $x_{0} \in X$ and $r$ be defined as in (3.1). If $T$ satisfies the following conditions, then $T$ fixes the closed ball $B_{\left\{u_{1}, u_{2}, \ldots, u_{d}\right\}}\left[x_{0}, \rho\right]$ with $\rho \leq r$ (or $B_{\left\{u_{1}, u_{2}, \ldots, u_{d}\right\}}\left[x_{0}, r\right]$ is the fixed disc of $\left.T\right)$ :

(1) If $T x \neq x$ then

$$
\|T x-x, u\|_{c} \leq \varphi\left(\begin{array}{c}
\left\|x-x_{0}, u\right\|_{c}, \frac{\left\|x-T x_{0}, u\right\|_{c}+\|T x-x, u\|_{c}}{2}, 0 \\
\|T x-x, u\|_{c}+\left\|x-T x_{0}, u\right\|_{c}
\end{array}\right)
$$

where $\varphi \in \Phi$.

(2) $T x_{0}=x_{0}$.

Proof. The proof can be easily seen by the similar arguments used in the proof of Theorem 3.2.

\section{References}

[1] Abdeljawad, T., Karapınar, E. and Taş, K., Common fixed point theorem in cone Banach space. Hacet. J. Math. Stat. 40 (2011), no. 2, 211-217.

[2] Gujetiya, R. K., Mali, D. K. and Hakwadiya, M., Common fixed point theorem for compatible mapping on cone Banach space. Int. J. Math. Anal. 8 (2014), no. 35, 1697-1706.

[3] Huang, L. G. and Zhang, X., Cone metric spaces and fixed point theorems of contractive mappings. J. Math. Anal. Appl. 332 (2007), 1468-1476.

[4] Karapinar, E., Fixed point theorems in cone Banach spaces. Fixed Point Theory Appl. 2009, Article ID 609281, 9 pages. doi:10.1155/2009/609281.

[5] Krishnakumar, R. and Dhamodharan, D., Common fixed point of contractive modulus on 2-cone Banach space. Malaya J. Mat. 5 (2017), no. 3, 608-618.

[6] Mlaiki, N., Çelik, U., Taş, N., Özgür, N. Y. and Mukheimer, A., Wardowski type contractions and the fixed-circle problem on $S$-metric spaces. J. Math. 2018, Art. ID 9127486, 9 pp.

[7] Mlaiki, N., Taş, N. and Özgür, N. Y., On the fixed-circle problem and Khan type contractions. Axioms 7 (2018), 80.

[8] Özgür, N. Y. and Taş, N., Some fixed-circle theorems on metric spaces. Bull. Malays. Math. Sci. Soc. (2017). https://doi.org/10.1007/s40840-017-0555-z

[9] Özgür, N. Y. and Taş, N., Fixed-circle problem on $S$-metric spaces with a geometric viewpoint. arXiv:1704.08838

[10] Özgür, N. Y., Taş, N. and Çelik, U., New fixed-circle results on S-metric spaces. Bull. Math. Anal. Appl. 9 (2017), no. $2,10-23$.

[11] Özgür, N. Y. and Taş, N., Some fixed-circle theorems and discontinuity at fixed circle. AIP Conference Proceedings, 1926, 020048 (2018). 
[12] Özgür, N. Y., Fixed-disc results via simulation functions. arXiv:1901.02623

[13] Pant, R. P., Özgür, N. Y. and Taş, N., On discontinuity problem at fixed point. Bull. Malays. Math. Sci. Soc. (2018). https://doi.org/10.1007/s40840-018-0698-6.

[14] Pitchaimani, M. and Ramesh Kumar, D., Some common fixed point theorems using implicit relation in 2-Banach spaces. Surv. Math. Appl. 10 (2015), 159-168.

[15] Rada, E. and Tato, A., An extension of a fixed point result in cone Banach space. Pure and Applied Mathematics Journal 4 (2015), no. 3, 70-74.

[16] Şahiner, A. and Yiğit, T., 2-cone Banach spaces and fixed point theorem. Numerical Analysis and Applied Mathematics ICNAAM 2012 AIP Conf. Proc. 1479 (2012), 975-978. doi: 10.1063/1.4756305

[17] Şahiner, A., Fixed point theorems in symmetric 2-cone Banach space $\left(l_{p},\|, .,\|_{p}^{c}\right)$. J. Nonlinear Anal. Optim. 3 (2012), no. 2, 115-120.

[18] Taş, N., Suzuki-Berinde type fixed-point and fixed-circle results on $S$-metric spaces. J. Linear Topol. Algebra 7 (2018), no. 3, 233-244.

[19] Tas,, N., Various types of fixed-point theorems on S-metric spaces. J. BAUN Inst. Sci. Technol. 20 (2018), no. 2, 211-223.

[20] Taş, N., Özgür, N. Y. and Mlaiki, N., New types of $F_{C}$-contractions and the fixed-circle problem. Mathematics 6 (2018), no. 10, 188.

[21] Taş, N. and Özgür, N. Y., Some fixed-point results on parametric $N_{b}$-metric spaces. Commun. Korean Math. Soc. 33 (2018), no. 3, 943-960.

\section{Affiliations}

\section{DHAMODHARAN}

AdDress: Jamal Mohamed College (Autonomous), Dept. of Mathematics, Tiruchirappalli-620020, Tamil NaduIndia.

E-MAIL: dharan_raj28@yahoo.co.in

ORCID ID: 0000-0003-4859-4816

NIHAL TAŞ

AdDress: Balıkesir University, Dept. of Mathematics, 10145, Balıkesir-Turkey.

E-MAIL: nihaltas@balikesir.edu.tr

ORCID ID: 0000-0002-4535-4019

R. KRISHNAKUMAR

AdDRESS: Urumu Dhanalakshmi College, Dept. of Mathematics, Tiruchirappalli-620019, Tamil Nadu-India.

E-MAIL: srksacet@yahoo.co.in

ORCID ID: 0000-0001-5927-0150 